\title{
Chapter
}

\section{CHITOSAN AND FISH COLLAGEN AS BIOMATERIALS FOR REGENERATIVE MEDICINE}

Yoshihiko Hayashi, Shizuka Yamada, Kajiro Yanagiguchi, Zenya Koyama, Takeshi Ikeda

\section{TABLE OF CONTENTS}

1. Introduction

2. General Properties of Scaffold for Regenerative Medicine

3. Chemical and Physical Properties of Scaffold

3.1Chitosan

3.1.1 Degree of Deacetylation and Molecular Weight

3.1.2 Cross-linking with Bioactive Agents

3.1.3 Mechanical Strength

3.2 Fish Collagen

3.2.1 Amino Acids Composition

3.2.2 Degeneration Temperature

3.2.3 Cross-linking for Stability

3.2.4 Mechanical Strength

4. Biocompatibility and Allergy

5. Biodegradation

6. Conclusions

References

Running title: Chitosan and Fish Collagen as Biomaterials 


\section{Summary}

This chapter focuses and reviews on the characteristics and biomedical application of chitosan and collagen from marine products, and advantage and disadvantage for regeneration medicine. The understandings of the production processes and the conformation of these biomaterials are indispensable for promoting the theoretical and practical availability. The initial inflammatory reactions associated with chitosan application to hard and soft tissues needs to be controlled before it can be considered for clinical application as scaffold. Furthermore, as it takes too long period for biodegradation of implanted chitosan in vivo, generally chitosan is concluded to be not suitable for the scaffold for degenerative medicine in especially dental pulp tissue surrounding hard tissue. The collagen extract from the scales of a tropical fish, has been reported to have a degeneration temperature of $35^{\circ} \mathrm{C}$. The properties of biocompatibility and biodegardation of fish atelocollagen are suitable for the scaffold in regenerative medicine.

Key Words: Chitosan, Fish collagen, Biocompatibility, Biodegradation Scaffolds, Regenerative medicine 


\section{INTRODUCTION}

The regenerative medicine consists of three components, cell, nutrient, and scaffold. The combinatory usage of these components is important. For the scaffold manufacturing, bioactive natural organic materials originated from marine products are indispensable because the severe inflectional problems such as bovine spongiform encephalopathy, avian and swine influenzas, and tooth-and-mouth disease in bovine, pig, and buffalo occur all over the world.

Chitin is mainly contained in the shells of crabs and shrimps. Chitosan is produced because of deacetylation of chitin. Chitosan has numerous pharmacological actions, such as immunopotentiation, antihypertensive, serum cholesterol-lowering, antibacterial, and wound healing-promoting properties (Asaoka 1996, Koide 1998). These biological effects would be favorable for scaffold fabrication. Furthermore, marine collagen from fish scales, skin, and bone has been widely investigated to apply as a scaffold and a carrier because of its bioactive properties such as its excellent biocompatibility, low antigenicity, high biodegradability, and cell growth potential (Dillow and Lowman 2002, Yang et al., 2001). 
This chapter focuses and reviews on the characteristics and biomedical application of chitosan and collagen from marine products, and advantage and disadvantage for regeneration medicine. The understandings of the production processes and the conformation of these biomaterials are indispensable for promoting the theoretical and practical availability.

\section{GENERAL PROPERTIES OF SCAFFOLD FOR REGENERATIVE}

\section{MEDICINE}

The basic principle of tissue engineering is that cells, genes, and proteins are delivered via a degradable material, termed a scaffold, to regenerate tissue. This concept was first elucidated by Langer R, Vacanti J, Griffith L, and their colleagues (Langer et al., 1990, Langer and Vacanti 1993, Langer and Vacanti 1999, Cima et al., 1991). In those papers, they laid out the basic requirements for the scaffold, as 1) choosing a material for a support matrix that was biocompatible and could be readily processed into desired shapes, 2) characterizing cell interaction with the material based on the tissue structural and metabolic demands, and 3) evaluating the performances of the matrices in vitro and 
in vivo through quantitative molecular and histological assays. These principles laid the foundation for tissue-engineering scaffold research and development.

The scaffold functions to a) provide structural integrity and to define a potential space for the engineered tissue, b) guide the restructuring that occurs through the proliferation of the donor cells and in-growth of the host tissue, c) maintain distances between the parenchymal cells that permit diffusion of the gas and nutrients and possibly, the in-growth of vasculature from the host bed, and d) transimit the tissue-specific mechanical forces to cue the behavior of the cells within it (Marler et al., 1998). Based on these functions as a scaffold, the sponge form is suitable and reasonable for the scaffold structure (Madihally and Matthew 1999).

Beyond knowing what parameters can influence tissue regeneration, it is difficult to know what quantitative measures can be used to characterize these regeneration-enhancing parameters. Three scaffold-design parameters are accepted as influencing tissue regeneration: i) modification of scaffold surfaces to enhance cell interaction, ii) controlled release of growth factors from scaffolds, and 
iii) scaffold mass transport (Hollister 2009).

Enhancing tissue regeneration by controlling cell-scaffold interaction and the necessity to accommodate cellular metabolic demands through scaffold diffusivity were two fundamental scaffold-design requirements enunciated in the early 1990s (Langer et al., 1990, Cima et al., 1991).

Scaffold mass transport can be characterized by scaffold diffusively and permeability. As with mechanical properties, native tissue diffusivity and permeability can be regarded as a starting point for defining scaffold-transport design targets (Hollister 2009). One of the major effects of designed diffusivity and permeability is to affect oxygen diffusion to cells and regenerate tissues. Partial oxygen pressure is a factor clearly affected by scaffold mass-transport characteristics that can affect cell differentiation. Most studies on differentiation of progenitor cells or behavior of fully differentiated cells reflect required permeability and diffusivity values (Domm et al., 2002, Malda et al., 2004).

\section{CHEMICAL AND PHYSICAL PROPERTIES OF SCAFFOLD}

\subsection{Chitosan}




\subsubsection{Molecular Weight (MW) and Degree of Deacetylation (DD)}

The term chitosan describes a series of chitosan polymers with different MW, viscosity and DD (40-98\%). It is a linear polyamine with a number of amino groups that are readily available for chemical reaction and salt formation with acids. Important characteristics of chitosan are its molecular weight, viscosity, DD (Bodek 1994; Ferreira et al., 1994a, b), crystallinity index, number of monomeric units, water retention value, pKa and energy of hydration (Kas 1997). Chitosan has a high charge density, adheres to negatively charged surfaces, and chelates metal inons.

The MW of chitosan is affected by deproteinization conditions used for the isolation of the chitonous substrate. It is difficult to prepare a chitosan with a DD higher than $90 \%$ without significant degradation of polysaccharide molecules. It was also reported that the relationship of attachment and growth of any cells with a percentage of acetylation of chitosan followed a general trend with the higher deacetylated chitosan supporting attachment and subsequent growth of the cultured cells (Prasitsilp et al., 2000). The DD of chitosan and MW changes caused by process conditions influence the properties important for many 
applications, such as solubility of the product in dilute acids, viscosity of the obtained solutions, as well as on their biological activity.

Generally, the MW of chitosan exerts a major influence on its biological and physicochemical characteristics. The potential of chitosan $(\mathrm{MW}<5,000$ to 10,$000 ;$ DD 55.3-65.4\%) in gene delivery was investigated by Richardson and co-workers (1999). Chitosan molecular mass fraction were observed to readily complex DNA even down to a chitosan : DNA charge ratio of $1: 0.1$, which also resulted in a significant decrease in the degradation by DNase II with no degradation being apparent at a charge ratio of $1: 1$. Gene delivery studies have shown that siRNA transfection efficiency can be modulated by the MW of chitosan, and since the MW affects polymer chain entanglement, this in turn influences its complexing ability with negatively charged siRNA. For instsnce, high MW chitosan will entangle siRNA more readly than low MW chitosan, which results in binding siRNA more efficiently and protecting the condensed siRNA from enzymatic degradation and serum components.

Liu et al., (2007) found that size, zeta potential, morphology and 
complex stability as well as in vitro gene silencing of chitosan/siRNA nanoparticles were dependent on MW and DD. High MW and high DD samples produced stable nanoparticles, while those prepared with low MW (10 kDa) and an nitrogen/phosphorus (N/P) charge ratio of 50 showed almost no knockdown of endogenous EGFP in H1299 human lung carcinoma cells. On the other hand, nanoparticles prepared from MWs in the range of $65-170 \mathrm{kDa}$ and a $\mathrm{DD}$ of $80 \%$ showed a gene-silencing efficiency between $45 \%$ and $65 \%$. The highest gene-silencing efficiency of $80 \%$ was achieved when using an N/P ration of 150 for MWs of 114 and $170 \mathrm{kDa}$ having a DD of $84 \%$.

Fernandez-Urrusuno et al (1999) investigated the potential of chitosan (molecular weight $<50,000-130,000 ;$ DD $70-87 \%$ ) nanoparticles as a system for improving the systemic absorption of insulin following nasal instillation. Nanoparticles prepared by ionotropic gelation with tripolyphosphate enhanced the nasal absorption of the peptide to a greater extent than an aqueous solution of chitosan in a conscious rabbit model by monitoring the plasma glucose levels. The amount and molecular weight of chitosan did not have a significant effect on insulin release. 
LeHoux and Grondin (1993) investigated the effects of chitosan on plasma and liver cholesterol levels, liver weight and 3-hydroxy-3-methylglutaryl coenzyme A reductase in rats fed on a sterol diet ( $1 \%$ cholesterol and $0.2 \%$ cholic acid). Chitosan at a level of $5 \%$ lowered plasma and liver cholesterol levels by $54 \%$ and $64 \%$, respectively. High molecular weight chitosan (>750 kDa) had less hypocholesterolemic potential than a $70 \mathrm{kDa}$ preparation.

\subsubsection{Cross-linking with Bioactive Agent}

Growth factors including platelet-derived growth factor-BB, insulin-like growth factor, and transforming growth factor- $\beta$ function as modulators to promote wound healing, cell proliferation, and bone regeneration (Hollinger 1993, Park et al., 1998). Typical cross-linker binding chitosan polymer with these growth factors is tripolyphosphate pentasodium at 5\% (Park et al., 2000, Lee et al., 2000). This chemical cross-linking procedure brings the development of drug delivery system using chitosan scaffold.

\subsubsection{Mechanical Strength}

Mechanical properties of scaffold can be evaluated similarly to those of 
biomaterials in medicine and dentistry.

1) Tensile test (Tomihata and Ikada 1997, Chen et al., 2009)

Measurement is conducted after swelling with phosphate-buffered saline (PBS). The scaffold is subjected to tensile test using an Autograph (cross-head speed: $10 \mathrm{~mm} / \mathrm{min}$ ). The tensile strength is calculated as the breaking load divided by the initial cross-sectional area. A 250-400 $\mathrm{g} / \mathrm{mm}^{2}$ of tensile strength are reported in chitosan with a DD higher than $60 \%$.

2) Compression test (Subramanian and Lin 2005)

Scaffold is rehydrated in deionized water before the test. The test is performed on a special machine. The cross-head speed is $2 \mathrm{~mm} / \mathrm{min}$ and a 50-kgf load cell is used. The load (kgf)-displacement (mm) data are recorded by the computer software and converted to stress-strain curves to obtain elastic modulus ( $\mathrm{kPa}$ ). The crosslinked scaffolds have about 2-5 times higher elastic modulus (7.4-19.9 $\mathrm{kPa})$ compared to uncrosslinked scaffolds $(3.8 \mathrm{kPa})$.

3) Load-displacement test (Depan et al., 2011)

The scaffold is evaluated in the dry state by the depth sensing 
indentation approach using a nanoindentor. A maximum load of $0.15 \mathrm{mN}$ is set and 15 indents are made at $35 \mu \mathrm{m}$ intervals for each sample. The maximum indentation depth is set to $1000 \mathrm{~nm}$. The load-displacement data are recorded continuously through one complete cycle of loading and unloading. Young's modulus is $0.06-0.1 \mathrm{GPa}$ in chitosan and derivatives.

\subsection{Fish Collagen}

\subsection{Amino Acids Composition}

Biochemical composition of marine collagen is thought to be different from that of mammalian collagen. For biochemical analyses, the strict condition for sample preservation is important and indispensable before collagen extraction. This means that the hydroxyproline content in relation to collagen stability strongly depends on these sampling procedures (Swatschek et al., 2002). Several works showed that amino acid composition of fish collagens was almost similar to that of mammalian collagens (Kimura 1983, Kimura et al., 1988, Nagai et al., 2001, Nagai et al., 2004, Bae et al., 2008). Glycine was the most abundant amino acid and accounted for more that $30 \%$ of all amino acids. 
Furthermore, the degree of hydroxylation of proline was calculated to be 40-48\%, which was also similar level to that of the mammalian (about 45\%). The linear relationship between collagen stability and hydroxyproline content was demonstrated by that the degree of hydroxylation (Table 1) of proline in the fish collagen peptides was calculated to be about 35\% (personal communication from the laboratory of Prof. Yamauchi M, University of North Carolina Oral health Institute). Furthermore, it is very interesting that the degree of hydroxylation of proline of fishes in cold sea, for example chum salmon, was reported low level (35-37\%) (Kimura et al., 1988, Matsui et al., 1991) compared to that of fishes in relatively warm sea, which is related to the denaturation temperature of fishes (see next paragraph).

\subsubsection{Degeneration Temperature}

Fish collagen fibrillar gels have not been studied, with the exception of shark collagen (Nomura et al., 2000a, b), probably due to their low denaturation temperature (Td), which renders these materials difficult to handle. The Td of shark collagen solution is approximately $30^{\circ} \mathrm{C}$ (Nomura et al., 1995), which results in the dissolution of the fibrillar gel of this 
collagen at $37^{\circ} \mathrm{C}$ (Nomura et al., 2000a). This indicates that the gel could not be practically used at the actual physical temperature of human medical application. The $\mathrm{Td}$ of chum salmon is approximately $19^{\circ} \mathrm{C}$ (Kimura et al., 1988, Matsui et al., 1991), which is the main reason to be unstable at the actual physical temperature of human body. As the denaturation temperature of fish collagen is lower than the mammalian body temperature, fish collagen melts when placed in contact with the human body for a clinical application. Recently, collagen extract from ray skin or the scales of a tropical fish (tilapia), has been reported to have a Td of $33-34^{\circ} \mathrm{C}$ (Bae et al., 2008) and $35^{\circ} \mathrm{C}$ (Ikoma et al., 2003), respectively. Furthermore, the improvement can be achieved by chemical cross-linking in vitro collagen fibrillogenesis. This method brings Td of salmon collagen to $55^{\circ} \mathrm{C}$ and its biocompatible properties have been demonstrated by several studies (Nagai et al., 2004, 2007).

\subsubsection{Cross-linking for Stability}

Numerous attempts have been recently made to use type I collagen for biomaterials. The cross-linking methods for stabilization of collagen are divided into physical treatment such as ultraviolet irradiation (Weadock 
et al., 1995), dehydrothermal treatment (Weadock et al., 1995, Gorham et al., 1992, Koide et al., 1993, Wang et al., 1994, Pieper et al., 1999), and treatments involving chemical such as glutaraldehyde (White et al., 1973), carbodiimide (Pieper et al., 1999), and 1-ethyl-3-(3-dimethylaminopropyl)-carbodiimide (EDC) (Yunoki et al., 2004). Chemical treatments confer remarkably high strength and stability to the collagen matrix, but may result in potential cytotoxicity or poor biocompatibility (Huang-Lee et al., 1990), while physical treatments have no cytotoxicity and can provide sufficient stability (Koide et al., 1993, Yunoki et al., 2003).

\subsubsection{Mechanical Strength}

Compression test is a typical method for measuring mechanical strength of collagen (Lee et al., 2001, Sugiura et al., 2009, Lyons et al., 2010). The collagen sponges are soaked in PBS, immediately degassed and subjected to test. The specimens are compressed using a cylindrical probe at a cross-head speed of $0.2 \mathrm{~mm} / \mathrm{s}$ to achieve a strain of $50 \%$ and immediately returned to the original position. The compressive modulus is calculated from the slope of the stress-strain curve in the linear region 
(strain below 15\%). Modules are different (6.7-30.9 $\mathrm{kPa}$ ) dependeding on the cross-linked conditions.

\section{Biocompatibility and Allergy}

\subsection{Chitosan}

Chitosan has potentially pro-inflammatory properties through the release of chemical mediators (Usami et al., 1998, Bianco et al., 2000). Histological findings indicate that this material stimulates the migration of polymorphonuclear leukocytes and macrophages (Peluso et al., 1994, Usami et al., 1994, Minami et al., 1997), and promotes angiogenesisi, reorganization of the extracellular matrix and granulation tissue formation (Minami et al., 1993, Okamoto et al., 1993).

Crustaceans are consumed in many coastal countries. In Japan, large amounts of shrimp, lobster, spiny lobster, and crab are imported from Asian countries and many other regions, and are processed as materials for commercial foods. Crustaceans are well-known allergens, and several clinical cases have been reported (Lehrer et al., 2003, Opinion of the Scientific Panel 2004). It is known that crustacean allergy generally 
presents as skin and respiratory tract symptoms. Furthermore, anaphylaxis can be induced in sensitive patients by the intake of trace amounts of crustacean (Tomikawa et al., 2006, Department of Food Safety 2002). Although the wound dressing material originated from crab shell has been clinically used over 25 years in Japan, fortunately, there are no allergic reports or side effects. This should be brought through the good product managements including the process of deproteoinization.

\subsection{Collagen}

An IgE-reactive protein was clinically observed in surimi from walleye pollack, one of fish foods, by ELISA using one patient serum positive to the high molecular weight allergen suggesting it to be collagen (Hamada et al., 2000). It is provided that the evidence that the high molecular weight allergen recognized by plural patient sera is collagen, and in competitive ELISA inhibition experiments, the big eye tuna collagen almost completely inhibited the IgE reactivity to the heated extracted from five species of fish (Hamada et al., 2001). Some fish-sensitive patients possessed IgE antibody to fish gelatin. Fish gelatin (type I collagen) might be an allergen in subjects with fish allergy (Sakaguchi et 
al., 2000). Atelocollagen is a processed natural biomaterial produced from bovine type I collagen. It inherits useful biomaterial characteristics from collagen, such as rare inflammatory responses, a high biocompatibility, and a high biodegradability (Miyata et al., 1992, Hanai et al., 2006). The parts of collagen that are attributed to its immunogenicity, namely telopeptides, are eliminated in the process of atelocollagen production. Therefore, atelocollagen possesses little immunogenicity (Sano et al., 2003). If substantial amounts of collagen could be obtained from fish wastes (scale, skin, and bone), they would provide an alternative to bovine collagen in food, cosmetics, and biomedical materials.

Jellyfish collagen scaffolds had a highly porous and interconnected pore structure, which is useful for a high-density cell seeding, an efficient nutrient and oxygen supply to the cells cultured in the three-dimensional matrices. To determine whether jellyfish collagen evokes any specific inflammatory response compared to that induced by bovine collagen or gelatin, the levels of pro-inflammatory cytokines and antibody secretions were measured and the population changes of immune cells after in vivo 
implantation. Jellyfish collagen was demonstrated to induce an immune response at least comparable to those caused by bovine collagen and gelatin (Song et al., 2006).

Elastic salmon collagen (SC) vascular grafts were prepared by incubating a mixture of acidic SC solution and a fibrillogenesis-inducing buffer containing a crosslinking agent, water-soluble carbodiimide (WSC). Subsequently, re-crosslinking in ethanol solution containing WSC was performed. Upon placement in rat subcutaneous pouches, the SC grafts brought little inflammatory reaction (Nagai et al., 2008).

Collagen sponges with micro-porous structures from tilapia were fabricated reconstituted collagen fibrils using freeze-drying and cross-linked by dehydrothermal treatment (DHT treatment) or additional treatment with WSC treatment. The pellet implantation tests into the paravertebral muscle of rabbits demonstrated that tilapia collagen caused rare inflammatory responses at 1 - and 4 -week implantation, statistically similar to those of porcine collagen and a high-density polyethylene as a negative control (Sugimura et al., 2009). 


\section{Biodegradation}

\subsection{Chitosan}

The cotton-like chitosan (MW: about $200 \mathrm{kDa}$; 35, 70, and 100\% DD) was implanted into the alveolar bone cavities. The histopathological examination was carried out at 1, 3, 6, 9, and 12 months after the implantation. All the various types of chitosans were degraded with time, in conjunction with the bone regeneration (Ikeda et al., 2002). However, it takes about 9 months after the implantation for the almost completely disappearance of chitosan in the bone tissue. Only the monomer type of chitosan, D-glcosamine which is effective to relieve the signs of osteoarthriris is easy to completely dissolve immediately in vitro and in vivo.

\subsection{Collagen}

Upon placement in rat subcutaneous pouches, the SC grafts were gradually and slowly biodegraded. At 1 month after implantation, fibroblasts and macrophages started penetrating the surface of the graft without exhibiting any signs of necrosis (Nagai et al., 2008). The biodegradation rates of both the collagen implants were similar, except 
for the DHT-treated tilapia collagen sponges at 1-week implantation. Various types of treated collagens did not disappear in the tissue even at 4-week implantation (Sugimura et al., 2009).

\section{Conclusions}

The initial inflammatory reactions associated with chitosan application to hard and soft tissues needs to be controlled before it can be considered for clinical application as scaffold. Furthermore, as it takes too long period for biodegradation of implanted chitosan in vivo, generally chitosan is concluded to be not suitable for the scaffold for degenerative medicine in especially dental pulp tissue surrounding hard tissue.

The properties of biocompatibility and biodegardation of fish atelocollagen are suitable for the scaffold in regenerative medicine. However, these phenomena strongly depend on the procedures for cross-linking. 


\section{References}

Asaoka, K. (1996). Chitin/Chitosan, The Choice Food Supplement for Over 10,000 Physicians in Japan. Vantage Press, New York.

Bae, I., Osatomi, K., Yoshida, A., Osako, K., Yamaguchi, A., Hara, K. (2008). Biochemical properties of acid-soluble collagen extracted from the skins of underutilized fishes. Food Chem. 108, 49-54.

Bianco, I. D., Balsinde, J., Beltramo, D. M., Castagna, L. F., Landa, C. A., Dennis, E. A. (2000). Chitosan-induced phospholipase $A_{2}$ activation and arachidonic acid mobilization in $\mathrm{P}_{388 \mathrm{D}_{1}}$ macrophages. FEBS Lett. 466, 292-294.

Bodek, K. H. (1994). Potentiometric method for determination of the degree of acetylation of chitosan. In"Chitin World” (Z. S. Karnicki, M. M. Breziski, P. J. Bykowsky, A. Wojtasz-Pajak, Eds.), pp. 456-461,. Wirtschaftsverlag NW-Verlag, Germany.

Chen, F., Su, Y., Mo, X., He, C., wang, H., Ikada, Y. (2009). Biocompatibility, alignment degree and mechanical properties of an electrospun chitosan-P(LLA-CL) fibrous scaffold. J. Biomater. Res. 20, 2117-2128.

Cima, L. G., Vacanti, J. P., vacant, C., Ingber, D., Mooney, D., Langer, R. (1991). Tissue engineering by cell transplantation using degradable polymer substrates. J. Biomech. Eng. 113, 143-151.

Depan, D., Venkata Surya, P. K. C., Girrase, B., Misra, R. D. K. (2011). Organic/inorganic hybrid network structure nanocomposite scaffolds based on grafted chitosan for tissue engineering. Acta Biomater. 7, 2163-2175.

Department of Food Safety (2002). The Ministry of health, labour and Welfare of japan, Notification No. 1106001.

Dillow, A. K. and Lowman, A. M. (2002). Biomimetic materials and design; biointerfacial strategies, tissue engineering, and targeted drug delivery. Marcel Dekker, Inc., New York.

Domm, C., Schunke, M., Christesen, K., Kurz, B. (2002). Redifferentiation of dedifferentiated bovine articular chondrocytes in alginate culture under low oxygen tension. Osteoarthritis cartilage 10, $13-22$

Fernandez-Urrusuno, R., Calvo, P., Remunan-Lopez, C., Vila-Jato, J. L., Alonso, M. J. (1999). Enhancement of nasal absorption of insulin using 
chitosan nanoparticles. Pharm. Res. 16, 1576-1581.

Ferreira, M. C., Marvao, M. R., Duarte, M. L., Domard, A., Nunes, T., Feio, G. (1994a). Chitosan degree of acetylation: Comparison of two spectroscopic methods ( ${ }^{13} \mathrm{C}$ CP/MAS NMR and dispersive IR)In"Chitin World" (Z. S. Karnicki, M. M. Breziski, P. J. Bykowsky, A. Wojtasz-Pajak, Eds.), pp. 456-461,. Wirtschaftsverlag NW-Verlag, Germany.

Ferreira, M. C., Marvao, M. R., Duarte, M. L., Domard, A., Nunes, T., Feio, G. (1994b). Optimisation of the measuring of chitin/chitosan degree of acetylation by FT-IR spectroscopy. In"Chitin World” (Z. S. Karnicki, M. M. Breziski, P.J. Bykowsky, A. Wojtasz-Pajak, Eds.), pp. 456-461. Wirtschaftsverlag NW-Verlag, Germany.

Gorham, S. D., Light, N. D., Diamond, A. M., Willins, M. J., Bailey, A. J., Wess, T. J., Leslie, N. J. (1992). Effects of chemical modifications on the susceptibility of collagen to proteolysis. II. Dehydrothermal crosslinking. Int. J. Biol. Macromol. 14, 129-138.

Hamada, Y., Genka, E., Ohira, M., nagashima, Y., Shiomi, K. (2000). Allergenicity of fish paste products and surimi from walleye Pollack. Shokuhin Eiseigaku Zasshi (in Japanese). 41, 38-43.

Hamada, Y., Nagashima, Y., Shiomi, K. (2001). Identification of collagen as a new fish allergen. Biosci. Biotechnol. Biochem. 65, 285-291.

Hanai, K., Takeshita, F., Honma, K., nagahara, S., maeda, M., Minakuchi, Y., Sano, A., Ochiya, T. (2006). Atelocollagen-mediated systemic DDS for nucleic acid medicines. Ann. N. Y. Acad. Sci. 1082, 9-17.

Hollinger, J. (1993). Factors for osseous repair and delivery: part I. J. Craniofac. Surg. 4, 102-108.

Hollister, S. J. (2009). Scaffold design and manufacturing: from concept to clinic. Adv. Mater. 21, 3330-3342.

Huang-Lee, L. L. H., Cheung, D. T., Nimni, M. E. (1990). Biochemical changes and cytotoxicity associated with the degradation of polymeric glutaraldehyde derived crosslinks. J. Biomed. Mater. Res. 24, 1185-1201.

Ikeda, T., Yanagiguchi, K., and Hayashi, Y. (2002). Application to dental medicine- In focus on dental caries and alveolar bone healing. BioIndustry 19, 22-30 (in Japanese).

Ikoma, T., Kobayashi, H., Tanaka, J., Walsh, D., Mann, S. (2003). 
Physical properties of type I collagen extracted from fish scales of Pagrus major and Oreochromis niloticas. Int. J. Biol. Macromol. 32, 199-204.

Kas, H. S. (1997). Chitosan: Properties, preparation and application to microparticlate systems. J. Microscopy 14, 689-711.

Kimura, S. (1983). Vertebrate skin type I collagen: comparison of bony fishes with lamprey and calf. Comp. Biochem. Physiol. B 74, 525-528.

Kimura, S., Zhu, X.-P., Matsui, R., Shinjoh, M., Takamizawa, S. (1988). Characterization of fish muscle type I collagen. J. Food Sci. 53, 1315-1318.

Koide, S. S. (1998). Chitin-chitosan: Properties, benehits and risks. Nutr. Res. 18, 1091-1101.

Koide, M., Osali, K., Konishi, J., Oyamada, K., Katakura, T., Takahashi, A., Yoshizato, K. (1993). A new type of biomaterial for artificial skin: dehydrothermally cross-linked composites of fibrillar and denatured collagen. J. Biomed. Mater. Res. 27, 79-84.

Langer, R., Cima, L. G., Tamada, J. A., Wintermantel, E. (1990). Future directions in biomaterials. Biomaterials 11, 738-745.

Langer, R., and Vacanti, J. P. (1993). Tissue engineering. Science 260, 920-926.

Langer, R., and Vacanti, J. P. (1999). Tissue engineering: the challenges ahead. Sci. Am. 280, 86-89.

LeHoux, J. G., and Grondin, Grondin, F. (1993). Some effects of chitosan on liver function in the rat. Endocrinology 132, 1078-1084.

Lee, Y.-M., park. Y.-J., Lee, S.-J., Ku, Y., Han, S.-B., Klokkevold, P. R., Chung, C.-P. (2000). The bone regenerative effect of platelet-derived growth factor-BB delivery with a chitosan/tricalcium phosphate sponge carrier. J. Periodontal. 71, 418-424.

Lee, C. R., Grodzinsky, A. J., Spector, M. (2001). The effects of cross-linking of collagen-glycosaminoglycan scaffolds on compressive stiffness, chondrocyte-mediated contraction, proliferation and biosynthesis. Biomaterials 22, 3145-3154.

Lehrer, S. B., Ayuso, R., Reese, G. (2003). Seafood allergy and allergen: A review. Marine Biotechnol. 5, 339-348.

Liu, X. D., Howard, K. A., Dong, M. D., Anderson, M. O., Rahbek, U. L., Johnsen, M. G., Hansen, O. C., besenbacher, F., Kjems, J. (2007). The 
influence of polymeric properties on chitosan/siRNA nanoparticle formation and gene silencing. Biomaterials 28, 1280-1288.

Lyons, F. G., Al-munajjed, A. A., Kieran, S. M., Toner, M. E., Murphy, C. M., Duffy, G. P., O’Brien, F. J. (2010). The healing of bony defects by cell-free collagen-based scaffolds compared to stem cell-seeded tissue engineered constructs. Biomaterials 31, 9232-9245.

Malda, J., van Blitterswijk, C. A., van Geffen, M., Martens, D. E., Tramper, J., Riesle, J. (2004). Low oxygen tension stimulates the redifferentiation of dedifferentiated adult human nasal chondrocytes. Osteoarthritis Cartilage 12, 306-313.

Marler, J. J., Upton, J., langer, R., Vacanti, J. P. (1998). Translation of cells in matrices for tissue regeneration. Adv. Drug Deliv. Rev. 33, 165-182.

Madihally, S. V., and Matthew, W. T. (1999). Porous chitosan scaffolds for tissue engineering. Biomaterials 20, 1133-1142.

Matsui, R., Ishida, M., kimura, S. (1991). Characterization of an $\alpha 3$ chain from the skin type I collagen of chum salmon (Oncorhynchus keta). Comp. Biochem. Physiol. B 99, 171-174.

Minami, S., Okamoto, Y., Tanioka, S., Sashiwa, H., Saimoto, H., Matsuhashi, A., Shigemasa, Y. (1993). Effects of chitosan on wound healing. In "Carbohydrates and Carbohydrate Polymers" (M. Yalpani, Ed.), pp. 141-152. ALT Press, Illinois.

Minami, S., Masuda, M., Suzuki, H., Okamoto, Y., Matsuhashi, A., kato, K., Shigemasa, Y. (1997). Subcutaneous injected chitosan induces systemic activation in dogs. Carbohydr. Polym. 33, 285-294.

Miyata, T., taira, T., Noishiki, Y. (1992). Collagen engineering for biomaterial use. Clin. Mater. 9, 139-174.

Nagai, T., Yamashita, E., Taniguchi, K., Kanamori, N., Suzuki, N. (2001). Isolation and characterization of collagen from the outer skin waste material of cuttlefish (Sepia lycidas). Food Chem. 78, 173-177.

Nagai, N., Yuniki, S., Suzuki, T., Sakata, M., Tajima, K., Munekata, M. (2004). Application of cross-linked salmon atelocollagen to the scaffold of human periodontal ligament cells. J. Biosci. Bioeng. 101, 511-514.

Nagai, N., Mori, K., Satoh, Y., Takahashi, N., Yunoki, S., Tajima, k., Munekata, M. (2007). In vitro growth and differentiated activities of human periodontal ligament fibroblasts cultured on salmon collagen gel. 
J. Biomed. Mater. Res. 82A, 395-402.

Nagai, N., Nakayama, Y., Zhou, Y.-M., Takamizawa, K., Mori, K., Munekata, M. (2008). Development of salmon collagen vascular graft: mechanical and biological properties and preliminary implantation study. J. Biomed. Mater. Res. 87B, 432-439.

Nomura, Y., Yamano, M., Shirai, K. (1995). Renaturation of $\alpha 1$ chains from shark skin collagentype I. J. Food Sci. 60, 1233-1236.

Nomura, Y., Toki, S., Ishii, Y., Shirai, K. (2000a). The physicochemical property of shark type I collagen gel and membrane. J. Agric. Food Chem. 48, 2028-2032.

Nomura, Y., Toki, S., Ishii, Y., Shirai, K. (2000b). Improvement of the material property of shark type I collagen by comparison with pig type I collagen. J. Agric. Food Chem. 48, 6332-6336.

Okamoto, Y., Minami, S., Matsuhashi, A., Sashiwa, H., Saimoto, H., Shigemasa, Y., Tanigawa, T., Tanaka, Y., Tokura, S. (1993). Application of polymeric N-acetyl-D-glucosamine (chitin) to veterinary practice. $J$. Vet. Med. Sci. 55, 742-747.

Opinion of the Scientific Panel on Dietetic Products, Nutritionand Allergies on a request from the Commission relating to the evaluation of allergic foods for labeling purpose, Request $\mathrm{N}^{\mathrm{O}}$ EFSA-Q-2003-016. (2004). EFSA J. 32, 52-58.

Park, Y. J., Ku, Y., Chung, C. P., Lee, S., J. (1998). Controlled release of platelet-derived growth factor from porous poly(L-lactide) membranes for guided tissue regeneration. J. Control. Release 51, 201-211.

Park, Y. J., Lee, Y. M., Park, S. N., Sheen, S. Y., Chung, C. P., Lee, S. J. (2000). Platelet derived growth factor releasing chitosan sponge for periodontal bone regeneration. Biomaterials 21. 153-159.

Peluso, G., Perillo, O., Ranieri, M., Santi, M., Ambrosio, L., Calabro, D., Avallone, B., Balsammo, G. (1994). Chitosan-mediated stimulation of macrophage function. Biomaterials 15, 1215-1220.

Pieper, J. S., Oosterhof, A., Dijkstra, P. J., Veerkamp, J. H., van Kuppevelt, T. H. (1999). Preparation and characterization of porous crosslinked collagenous matrices containing bioavailable chondroitin sulphate. Biomaterials 20, 847-858.

Prasitsilp, M., Jenwithisuk, R., Kongsuwan, K., Damrongchai, N., Watts, P. (2000). Cellular responses to chitosan in vitro: The importance of 
deacetylation. J. Mater. Sci. Mater. Med. 11, 773-778.

Richardson, S. C. W., Kolbe, H. V. J., Duncan, R. (1999). Potential of low molecular mass chitosan as a DNA delivery system. Biocompatibility, body distribution and ability to complex and protect DNA. Int. J. Pharm. 178, 231-243.

Sakaguchi, M., Toda, M., Ebihara, T., Irie, S., Hori, H., Imai, A., Yanagida, M., Miyazawa, H., Ohsuna, H., Ikezawa, Z., Inoue, S. (2000). IgE antibody to fish gelatin (type I collagen) in patients with fish allergy. J. Allergy Clin. Immunol. 106, 579-584.

Sano, A., Maeda, M., Nagahara, S., Ochiya, T., Honma, K., Itoh, H., Miyata, T., Fujioka, K. (2003). Atelocollagen for protein and gene delivery. Adv. Drug. Delivery Res. 55, 1651-1677.

Song, E., Kim, S. Y., Chun, T., Byun, H.-J., Lee, Y. M. (2006). Collagen scaffolds derived from a marine source and their biocompatibility. Biomaterials 27, 2951-2961.

Subramanian, A., and Lin, H.-Y. (2005). Crosslinked chitosan: its physical properties and the effects of matrix stiffness on chondrocyte cell morphology and proliferation. J. Biomed. Mater. Res. 75A, 742-753.

Sugimura, H., Yunoki, S., Kondo, E., Ikoma, T., tanaka, J., Yasuda, K. (2009). In vito biological responses and bioresorption of Tilapia scale collagen as a potential biomaterial. J. Biomater. Sci. 20, 1353-1368.

Sugiura, H., Yunoki, S., Kondo, E., Ikoma, T., Tanaka, J., Yasuda, K. (2009). In vivo biological responses and bioresorption of tilapia scale collagen as a potential biomaterial. J. Biomater. Sci. 20, 1353-1368.

Swatschek, D., Schatton, W., Kellermann, J., Mullaer, W. E. G., Kreuter, J. (2002). Marine sponge collagen: isolation, characterization and effects on the skin parameters surface-pH, moisture and sebum. Eur. J. pharmaceut. Biopharmaceut. 53, 107-113.

Tomihata, K., and Ikada, Y. (1997). In vitro and in vivo degradation of films of chitin and its deacetylated derivatives. Biomaterials 18, 567-575.

Tomikawa, M., Suzuki, N., Urist, A., Tsuburai, T., Ito, S., Shibata, R., Ito, K., Ebisawa, M. (2006). Characteristics of shrimp allergy from childhood to adulthood in Japan. Jpn. J. Allergy 55, 1536-1542.

Usami, Okamoto, Y., Minami, S., matsuhashi, A., Kumazawa, N. H., Tanaka, S., Shigemasa, Y. (1994). Chitin and chitosan induce migration 
of bovine polymorphonuclear cells. J. Vet. Med. Sci. 56, 761-762.

Usami, Y., Okamoto, Y., Takayama, T., Shigemasa, Y., Minami, S. (1998). Chitin and chitosan stimulate canine polymorphonuclear cells to release leukotriene $\mathrm{B}_{4}$ and prostagrandin $\mathrm{E}_{2}$. J. Biomed. Mater. Res. 42, 517-522. Wang, M. C., Pins, G. D., Silver, F. H. (1994). Collagen fibers with improved strength for the repair of soft tissue injuries. Biomaterials 15, 507-512.

Weadock, K. S., Miller, F. J., Bellincampi, L. D., Zawadsky, J. P., Dunn, M. G. (1995). Physical crosslinking of collagen fibers: comparison of ultrabviolet irradiation and dehydrothermal treatment. J. Biomed. Mater. Res. 29, 1373-1379.

White, M. J., Kohno, I., Rubin, A. I., Stenzel, K. H., Miyata, T. (1973). Collagen films: effect of cross-linking on physical and biological properties. Biomater. Med. Dev. Art. Org. 1, 703-715.

Yang, A. F., Leong, K. F., Du, Z. H., Chua, C. K. (2001). The design of scaffolds for use in tissue engineering. Part 1 . Traditional factors. Tissue Eng. 7, 679-689.

Yunoki, S., Suzuki, T., Takai, M. (2003). Stabilization of low denaturation temperature collagen from fish by physical cross-linking methods. J. Biosci. Bioeng. 96, 575-577.

Yunoki, S., Nagai, N., Suzuki, T., Munekata, M. (2004). Novel biomaterial from reinforced salmon collagen gel prepared by fibril formation and cross-linking. J. Biosci. Bioeng. 98, 40-47. 


\section{Contributors}

\section{Yoshihiko Hayashi}

Department of Cariology

Graduate School of Biomedical Sciences

Nagasaki University

Nagasaki, Japan

\section{Shizuka Yamada}

Department of Cariology

Graduate School of Biomedical Sciences

Nagasaki University

Nagasaki, Japan

\section{Takashi Ikeda}

Department of Cariology

Nagasaki University Hospital

Nagasaki, Japan

\section{Kajiro Yanagiguchi}

Department of Cariology

Nagasaki University Hospital

Nagasaki, Japan

Corresponding author:

Yoshihiko Hayashi 
TABLE 1 Degree of hydroxylation

\begin{tabular}{lc}
\hline Fishes & $\%$ \\
\hline Squid & 47.8 \\
Carp & 43.3 \\
Eel & 40.2 \\
Common mackerel & 41.1 \\
Saury & 40.5 \\
Chum salmon & 38.0 \\
Tilapia & 43.0 \\
Tiger puffer & 34.5 \\
Dusky spinefoot & 37.6 \\
Sea chubs & 40.4 \\
Eagle ray & 41.6 \\
Red stingray & 46.9 \\
Yantal stingray & 40.6 \\
\hline
\end{tabular}

